Central Washington University

ScholarWorks@CWU

All Faculty Scholarship for the College of the Sciences

$5-2004$

Age-related Hearing Loss and its Association with Reactive Oxygen Species and Mitochondrial DNA damage

Michael D. Seidman

Nadir Ahmad

Dipa Joshi

Jake Seidman

Sujatha Thawani

See next page for additional authors

Follow this and additional works at: https://digitalcommons.cwu.edu/cotsfac

Part of the Otolaryngology Commons 
Authors

Michael D. Seidman, Nadir Ahmad, Dipa Joshi, Jake Seidman, Sujatha Thawani, and Wayne S. Quirk 


\title{
Age-related Hearing Loss and its Association with Reactive Oxygen Species and Mitochondrial DNA damage*
}

\author{
MICHAEL D. SEIDMAN ${ }^{1}$, NADIR AHMAD ${ }^{1}$, DIPA JOSHI ${ }^{2}$, JAKE SEIDMAN ${ }^{3}$, \\ SUJATHA THAWANI ${ }^{4}$ and WAYNE S. QUIRK ${ }^{5}$ \\ From the ${ }^{1}$ Henry Ford Health System, West Bloomfield, Michigan, ${ }^{2}$ Yale University, New Haven, Connecticut, ${ }^{3}$ Birmingham Groves, ${ }^{4}$ University \\ of Michigan, Ann Arbor, Michigan and ${ }^{5}$ Central Washington University, Ellensburg, Washington, USA
}

\begin{abstract}
Seidman MD, Ahmad N, Joshi D, Seidman J, Thawani S, Quirk WS. Age-related hearing loss and its association with reactive oxygen species and mitochondrial DNA damage. Acta Otolaryngol 2004; Suppl 552: 16-24.

Age-related hearing loss, known as presbyacusis, is characterized by the progressive deterioration of auditory sensitivity associated with the aging process and is the leading cause of adult auditory deficiency in the USA. Presbyacusis is described as a progressive, bilateral, high-frequency hearing loss that is manifested on audiometric assessment by a moderately sloping pure tone audiogram. Approximately $23 \%$ of the population between 65 and 75 years of age, and $40 \%$ of the population older than 75 years of age are affected by this condition. It was estimated in 1980 that $11 \%$ of the population was 76 years or older and this number is expected to almost double by the year 2030. When one considers that the population over 65 years of age is experiencing the most accelerated development of hearing loss, the potential socioeconomic ramifications are staggering. Curiously, the frequency of presbyacusis varies across different societies. This discrepancy has been attributed to many factors including genetics, diet, socioeconomic factors, and environmental variables. The purpose of this article is to review the various molecular mechanisms underlying presbyacusis and to offer insights into potential methods of mitigating the effects of aging on hearing impairment Key words: aging, mitochondrial DNA mutations, presbyacusis, reactive oxygen species.
\end{abstract}

\section{INTRODUCTION}

Aging is associated with a wide array of physiological, biochemical, and molecular changes including progressive DNA damage, deterioration of mitochondrial function, reduction of cellular water concentrations, ionic changes, vascular insufficiency, and decreased elasticity of cellular membranes. Studies have proposed that many factors contribute to this process, such as: altered vascular characteristics; reduced red blood cell velocity and vascular plasticity; increased vascular permeability $(1,2)$; reductions in oxygen and nutrient delivery and waste elimination (3-6); genetic mutations; and a significant presence of reactive oxygen species (ROS), otherwise known as free radicals. Concurrent with the increase in ROS is a decreased production or function of the endogenous enzymes that protect the cell against ROS damage including superoxide dismutase, catalase and glutathione peroxidase. These ROS have been shown to contribute in part to producing mitochondrial DNA (mtDNA) damage by causing deletions in the mitochondrial genome. These deletions are an important component of the age-associated diminution in auditory sensitivity. Specific deletions are known to be directly proportional to aging such as the common aging deletion in humans, which is 4977 base pairs in length (4834 base pairs in rats). When mtDNA

\footnotetext{
* Presented in part to: the Institute of Experimental Medicine Academy of Sciences, Czech Republic, 30 April 2003; and the Conference on Sensorineural Hearing Loss: Incites of Clinical Advances, Prague, 1 May 2003.
}

deletions reach a certain level, the mitochondria become bioenergetically inefficient. This inefficiency can be measured through reductions in specific enzymes (cytochrome oxidase (COX), succinate dehydrogenase $(\mathrm{SDH})$, nicotinamide adenine dinucleotide (NADH)), as well as by using flow cytometry to measure reductions in mitochondrial membrane potentials (MMP) (Fig. 1), which serves as a marker of mitochondrial function, and by the measurement of specific deletions or point mutations in the mitochondrial DNA genome. Fig. 1A and 1B are typical histograms of cell fluorescence in young and old rat lymphocytes $\left(10^{6}\right)$ incubated with $0.5 \mathrm{nM}$ DiOC $_{6}$. Preliminary results revealed a two- to threefold greater intensity of $\mathrm{DiOC}_{6}$ staining of peripheral blood lymphocytes (PBL) of young compared with old rats (Fig. 1C). Reductions in mitochondrial function and increases in mtDNA deletions have been identified within heart, brain, liver and skeletal muscle samples in aged rats, mice, monkeys and humans (7-11).

Aging thus involves the growing accumulation of metabolic and physiologic changes associated with an increasing susceptibility to disease. There are four main sources for failure of biological systems that may in part contribute to the aging processes.

1. Gene repression: essentially, this is a systematic, and probably programmed, age-dependent gene deterioration. Semsei et al. have demonstrated that increased intracellular potassium results in chromatin condensation with a consequent decline 

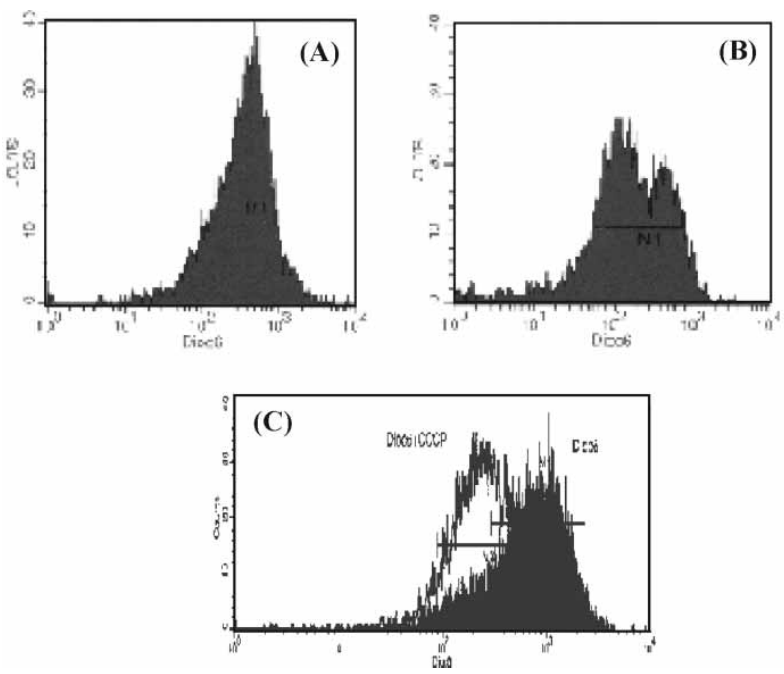

Fig. 1. Mitochondrial membrane potential (MMP) was studied by flow cytometry. 3,3'-Dihexyloxacarbocyanine $\left(\mathrm{DiOC}_{6}\right)$, which is used for the quantitative measurement of MMP, is a lipophilic, cationic, fluorescent probe. Peripheral blood lymphocytes (PBL) of young (6 months) and old (24 months) $\left(10^{6}\right)$ rats were equilibrated with very low concentrations $(0.5 \mathrm{nM})$ of $\mathrm{DiOC}_{6}$. (A) and (B) Typical histograms of cell fluorescence in young and old rat lymphocytes $\left(10^{6}\right)$ incubated with $0.5 \mathrm{nM} \mathrm{DiOC}_{6}$. There is a two- to threefold greater intensity of $\mathrm{DiOC}_{6}$ staining of PBL of young compared with old rats (C). The mean fluorescence of cells treated with and without carbonyl cyanide m-chlorophenylhydrazone (CCCP) $(20 \mu \mathrm{M})$ is shown in (C). Cells treated with CCCP consisted of low fluorescence, about $30 \%$ of control.

in RNA synthesis (12). This general decline in protein synthesis may in part account for the agedependent decrease in gene expression, leading to the turning off of specific biological systems. Hence, a threshold exists beyond which homeostasis begins to fail.

2. Intracellular communication: this is based upon the fact that cells require specific spatial arrangement which provides for the rapid transfer of molecules to neighboring cells. Any change in this spatial arrangement may lead to breakdown in cellular communication with resultant tissue aging, disease and death. It is known that mutations in connexin26, a gap junction protein, are responsible for a major form of non-syndromic recessive deafness and a more limited form of non-syndromic dominant hearing loss (13). It is possible that a similar mechanism may be involved in age-related hearing loss.

3. Waste accumulation: over time there are significant increases in waste products. The ability of cells to handle and process these products progressively decreases, hence, an increase in accretional defects, i.e. intima thickening, lipofuscin accumulation, and damaged collagen.

4. Age-related depletional defects: over time there is progressive breakdown of cellular function. When this accumulates with age, entire organ systems lose their normal function, often leading to disease states as well as normal physiologic aging (14).

There are many hypotheses in the current literature providing explanations for senescence. Three of the most convincing theories are the telomerase theory of aging, the dysdifferentiation hypothesis of aging and the membrane hypothesis of aging (MHA; also referred to as the 'mitochondrial clock theory' of aging).

The telomerase theory of aging suggests that there is a reduction in telomere length over time. The end of a chromosome is made up of a structure called the telosome. The tip of the telosome is a region of DNA repeat sequences and associated proteins collectively known as the telomere. It is hypothesized that DNA transcription and replication are affected by position effects mediated by the telomere. Reduction in the length of the telomere and alterations in its chromatin assembly may explain the instability that occurs during senescence as well as the immortalization process in vitro (15). In tumor-derived cell lines, telomeres are maintained by the ribonucleoprotein enzyme, telomerase. However, telomerase activity is repressed in practically all normal human somatic cells. Thus, there is an inherent problem of endreplication creating a tendency toward progressive telomere shortening. Cumulatively, this predilection leads to limited replicative capacity, chromatin instability and eventually, cellular senescence. Viral oncogenes or certain somatic mutations can block cellular aging probably by activating telomerase. Telomere shortening is therefore effectively prevented and this appears to be an important mechanism for sustaining the cellular growth of tumors (16). Lowlevel telomerase activity has also been demonstrated in normal human $\mathrm{T}$ and $\mathrm{B}$ cells, which was also shown to decrease with aging (17). Although many aspects of telomerase activity remain undefined, it has been hypothesized that the balance between telomere shortening and telomerase activity may underlie cellular aging processes. Therefore, although unproven, changes in telomeres may also predispose to the development of presbyacusis.

The dysdifferentiation theory suggests that aging is a continuum of programmed differentiation leading to either a cessation of normal gene activity or a systematic activation of genes whose effects are deleterious to cellular function. Support for this 
theory is provided by apoptosis (programmed cell death) studies in Caenorhabditis elegans (C. elegans) (earthworm). These experiments elegantly elaborated the genetic mechanisms responsible for controlling cell death. The maintenance of homeostasis for cellular metabolism and function consumes a large fraction of total body energy expenditure. This is engineered by the delicate balance between cellular proliferation and death. The $B c l-2$ gene, for example, exists in progenitor and long-lived cells and therefore appears to have a key function in the cells of the developing embryo. The gene appears to prevent oxidative damage to cellular organelles and lipid membranes. Studies have demonstrated that $\mathrm{Bcl}-2$ protects cells from the toxicity of $\mathrm{H}_{2} \mathrm{O}_{2}$ or t-butyl hydroperoxide in a dose-dependent manner $(18,19)$. Bcl-2-deficient mice demonstrate changes expected of more rapid cell death, including fulminant lymphoid apoptosis of systemic organs (20). $B c l-2$ also inhibits other types of apoptotic cell death, implying a common mechanism of lethality. Studies have demonstrated, for example, that $B c l-2$ protected cells from $\mathrm{H}_{2} \mathrm{O}_{2}$ and menadione-induced oxidative deaths $(18,21)$. Another protein that appears to operate as an accessory to $B c l-2$, is a $21 \mathrm{kd}$ protein referred to as Bax. In experiments by Hockenberry and colleagues, the suggested model of the ratio between $B c l-2$ and Bax appears to determine survival or death following an apoptotic stimulus. Specifically, elevated expression of $\mathrm{BCl}-2$ appears to be preventative, while that of Bax favors the apoptotic process.

Lastly, the membrane hypothesis of aging states that aging is related to decreasing effectiveness of cellular protective and reparative mechanisms. This yields biochemical and metabolic errors, which progressively accumulate resulting in cell death (22). The membrane hypothesis of aging (MHA) further postulates that cellular senescence is attributable to the cross-linking action of free oxygen radicals within the cellular membrane. Additionally, ROS lead to lipid peroxidation, polysaccharide depolymerization, nucleic acid disruption, and oxidation of sulfhydryl groups leading to enzyme inactivation (23). Therefore, the MHA suggests that ROS-induced cell membrane structural damage is the primary mediator in cellular aging (24, 25).

Careful analysis of the above mechanisms suggests that certain aspects of the three leading theories of aging may be interrelated. That is, free radical species lead to genetic and cellular alterations resulting in cellular dysfunction, and consequently senescence, and perhaps presbyacusis. It is even more intriguing to realize that a trigger for the Bax gene are the ROS (26). Thus, a critical analysis of the prominent hypotheses of aging suggests that aspects of all three theories are likely to apply. Specifically, the generation of ROS damages cellular integrity, which may lead to alterations in gene expression, including telomere shortening and activation of Bax genes, resulting in aging, presbyacusis and ultimately death.

As presbyacusis represents one aspect of aging, it is imperative thus to understand these molecular mechanisms of aging. In our laboratory, studies have focused on the mitochondrial theory of aging and its applicability to presbyacusis. There are, however, several animal models that have been used to study presbyacusis. These models have served to illuminate the various molecular mechanisms underlying agerelated hearing loss. One such model is the C57BL/6 J strain of mice, which demonstrates an age-dependent, high-frequency, sloping loss (27). The adult hearing loss (Ahl) gene, characterized as recessive and mapped to chromosome 10, has been identified in the C57 mouse strain and is the presumed cause of progressive hearing loss in this species. A proposed mechanism for this progressive hearing loss is that the $A h l$ gene mediates, through mRNA expression, a decrease in protective enzymes and therefore an increase in levels of oxidative stress within the period of time that the C57 mouse strain undergoes increased exposure to free radicals and its most significant diminution in hearing (28). More recently, the Ahl gene has also been implicated in noise-induced hearing loss (NIHL) (29).

In other studies, cochlear microphonic (CM) sensitivity has been shown to vary with age, with a gradual decrease in sensitivity from 12 to 24 months of age (30). Rat cochlear action potential (CAP) sensitivity has also been shown to decrease with age, and changes in CAP waveform with age have been shown (31). In a study of rat auditory brainstem response (ABR), delay in conduction times and waveform amplitude decreases were noted to occur in older animals (32). Our laboratory has studied groups of rats varying in age and has documented evidence of presbyacusis using changes in cochlear microcirculation, electrophysiology, molecular biology and histology $(33,34)$. Furthermore, histologic analysis of presbyacusis subjects demonstrate age-related hair cell degeneration and loss (35). Human studies reveal a preferential loss of outer hair cells (OHCs) $(36,37)$. Loss of OHCs is greatest in the first half of the basal turn $(36,38)$. This correlates tonotopically with the high-frequency loss seen in human presbyacusis. In the rat, age-related hair cell loss is also predominantly $\mathrm{OHC}$ in nature. In a study of elderly rats, inner hair cell (IHC) losses ranged from $3.1 \%$ to $9.2 \%$, while $\mathrm{OHC}$ losses ranged from $7.4 \%$ to $46.8 \%$. The IHC loss was greatest in the upper apex while $\mathrm{OHC}$ losses were greatest at the basal turn (39). While there are species-specific variations in cochleotopic patterns of hair cell loss, the rat is an appropriate aging model $(30,32,39)$ (Fig. 2). Several 


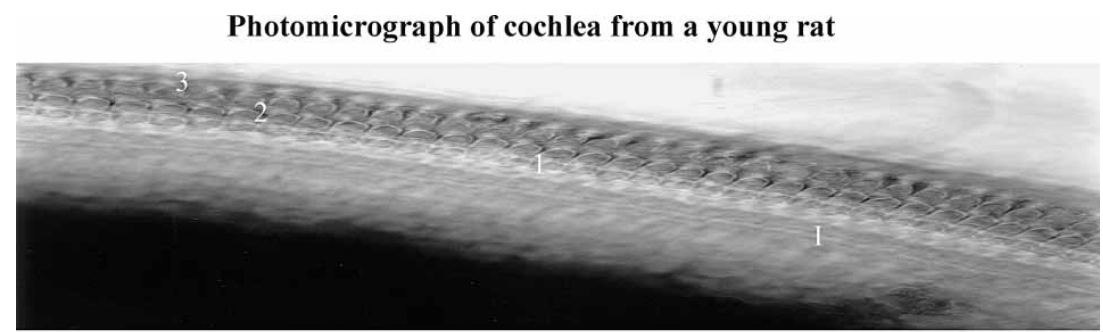

Photomicrograph of cochlea from old rat

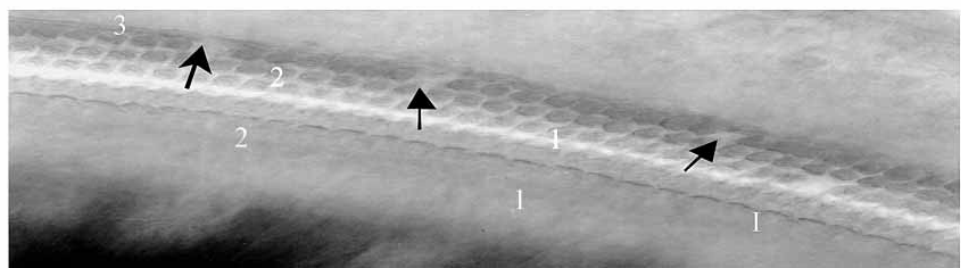

Fig. 2. Photomicrograph $(40 \times)$ of the cochlea from a representative animal. It shows a surface mount preparation of the basillar membrane of the right organ of Corti with osmium tetroxide staining from a 4-month old (A) and an 18month old (B) rat. Outer hair cell rows are shown by 1,2 , and 3 . 'I' denotes the single inner hair cell row. Loss of hair cells is denoted by arrows. No obvious hair cell pathology is noted in (A). Hair cell loss is shown in (B). human studies have also demonstrated accelerated hearing loss in patients with Alzheimer's disease and other cognitive and neurodegenerative disorders (40-42). There is a genetic predilection for Alzheimer's disease and perhaps these findings can be extrapolated to auditory dysfunction as well. As the formation of reactive oxygen species (ROS) and their subsequent effects on mitochondrial integrity are an integral mechanism in presbyacusis, it is important to consider these processes in greater detail.

\section{REACTIVE OXYGEN SPECIES (ROS)}

Reactive oxygen species (ROS) contain an unpaired number of electrons, making them chemically reactive and extremely toxic to cellular and subcellular structures. ROS have been implicated in more than 100 clinical conditions (43). They are produced in vivo during mitochondrial respiration, as well as via autooxidation of chemical and biological molecules. ROS are also environmental contaminants and can be formed from ionizing and ultraviolet radiation. The most common ROS are superoxide anion $\left(\mathrm{O}_{2}^{-}\right)$, hydroxyl radical $\left(\mathrm{OH}^{-}\right)$, hypochloride $\left(\mathrm{OCL}^{-}\right)$and nitric oxide $\left(\mathrm{NO}^{-}\right)$. Not only is the pathogenic role of ROS becoming acceptable in the realm of human disease, but their contribution as active participants in determining disease activity is also becoming increasingly recognized (44). Despite this primacy, ROS are notoriously difficult to quantify in biological systems. However, the use of modern assay techniques has made this less of a limitation (43).

There is extensive support in the literature for the protective effects of antioxidants and ROS scavengers. For example, tocopherols decrease the process of atherosclerosis and delay death from myocardial infarction, presumably by inhibiting lipid peroxidation (45). Carotenoids, such as $\beta$-carotene and other plant pigments, may also have preventive effects against cancer and cardiovascular disease (45-47).

Available data also suggest that many of the pathological correlates of Alzheimer's disease are precipitated by oxidative stress-induced mechanisms (48-50). Similarly, Parkinson's disease has also been associated with oxidative stress, increased lipid peroxidation, reduced levels of glutathione (GSH), high concentrations of iron, and free radical generation via auto-catalytic mechanisms within neuromelanin containing catecholaminergic neurons $(51,52)$. Recent studies have further demonstrated that aging in the central nervous system is directly correlated with oxidative stress. In the harlequin mouse model, mutations in the apoptosis-inducing factor (AIF) gene resulted in greater susceptibility to ROS-induced damage (53). A lack or down-regulation of AIF in neuronal cells renders them more sensitive to peroxides and to a much larger extent vulnerable to progressive increases in ROS-induced damage. This observation provides a molecular mechanism by which free radical damage can lead to neuronal death.

Many intrinsic enzyme systems protect cells from oxidative damage. These include superoxide dismutase (SOD), glutathione peroxidase, and the glutathione transferases, and catalase. Additionally, a variety of small molecules in the human diet are required for antioxidant defenses. Experimentally and clinically, it is well known that a primary source of ROS generation is through oxidative phosphorylation, ischemia/reperfusion or prolonged hypoperfusion, such as that seen in myocardial infarction, cerebrovascular accidents, 
aging, and possibly sudden sensorineural hearing loss and presbyacusis. It is clear that in the aging cochlea there is a significant reduction of blood supply and the ongoing need for energy generation through oxidative phosphorylation (2). Thus, these two processes, as well as others, allow for the generation of ROS within the cochlea.

\section{MITOCHONDRIAL DNA DELETIONS (MTDNA DEL) AND HEARING LOSS}

Mitochondria are unique organelles possessing their own DNA as well as their own enzymatic constituents to allow for transcription and translation of genetic information into proteins. Each mtDNA codes for a complete set of ribosomal (rRNA) and transfer RNA (tRNA). Additionally, mtDNA codes for 13 of the approximately 60 polypeptides necessary for oxidative phosphorylation. These include seven of the 25 subunits of respiratory complex I (ND1-4, 4L, 5, and 6)(NADH-ubiquinol-oxidoreductase), one of the approximately nine subunits (cyt b) of respiratory complex III (ubiquinol-cytochrome c oxidoreductase), three of the 13 subunits of respiratory complex IV (COI, COII, and COIII) (cytochrome c oxidase), and two of the 12 subunits of respiratory complex V (ATP6 and 8) (ATP synthase). The remaining subunits of these complexes are encoded by nuclear DNA (54-56)

It has been proposed that mitochondrial genomic mutations may be a major cause of human diseases. In 1959 , the first patient with a mtDNA deletion as a cause of their illness was reported by Ernster. Luft is often credited with recognizing the importance of mitochondrial medicine in 1962. Mitochondrial mutations and subsequent cytoplasmic segregation contribute to neuromuscular disorders such as KearnsSayre/chronic external ophthalmoplegia plus syndrome (57-60), mitochondrial encephalomyopathy, lactic acidosis, and stroke-like episodes (MELAS) (61), subacute necrotizing encephalomyopathies (SNE, Leigh syndrome), progressive neuronal degeneration of childhood (Alpers syndrome) (59), and myoclonic epilepsy associated with ragged-red muscle fibers (MERRF) $(54,62)$. Interestingly, up to $67 \%$ of patients with mtDNA disorders also manifest sensorineural hearing loss (63).

Mitochondrial DNA deletions with subsequent segregation and enrichment of the deletions throughout life are contributing factors in the aging process $(9,64,65)$. MtDNA deletions in the human heart are age-dependent (9), and these mitochondrial mutations accumulate progressively until death. Cells that accumulate large numbers of mitochondrial mutations become bioenergetically deficient. This compromised energy state explains their important role in many human diseases (57). MtDNA deletions accumulate preferentially in post-mitotic tissues such as the inner ear, retina, skeletal muscle and brain. This appears to account for the increased susceptibility of these tissues to hypoxia, ischemia and aging. Richter has shown that extensive oxidative damage occurs to mitochondrial and nuclear DNA, and has identified the presence of 8-hydroxydeoxyguanosine $\left(\mathrm{OH}^{8} \mathrm{dG}\right)$ in mtDNA and nuclear DNA (nDNA). This compound is formed by excited oxygen species and is considered a marker for DNA damage. Mitochondria treated with prooxidants have an increased level of $\mathrm{OH}^{8} \mathrm{dG}$. This increased level may be caused by several factors, including extensive oxygen metabolism, inefficient DNA repair and lack of mitochondrial histones. Studies have shown that increasing amounts of ROS occur as a function of age, which lead to an increase in membrane peroxide content and, thus, rapidly exceeds the capacity of homeostatic protection (66). Thus, there is extensive support that mtDNA deletions accumulate with age and disease (67-69).

Deafness is clearly shown to have an association with mtDNA mutations. It has been suggested that mitochondrial diseases should be considered in cases of progressive sensorineural hearing loss, especially those associated with multisystem involvement (70, 71). A $10.4 \mathrm{~kb}$ mtDNA deletion has been identified in association with maternally transmitted diabetes and deafness, without ophthalmoplegia or mitochondrial myopathies, which were the hallmark of mtDNA deletion syndromes (72). Other studies have identified mutations in the tRNA Leu(UUR) gene in a large pedigree with maternally inherited diabetes mellitus type II and deafness (73). A 3243 point mutation $(A \rightarrow G)$ has been demonstrated in a patient with sensorineural deafness without diabetes (74). Several human studies have demonstrated an association of mitochondrial DNA mutations and presbyacusis, including a study which demonstrated that older patients with presbyacusis had a higher frequency of the common aging deletion (4977 bp) compared with similar aged patients without presbyacusis (75). It has been demonstrated, using human archival temporal bones, that 14 of 17 aged patients with presbyacusis had the 4977 bp deletion compared with 8 of 17 control patients with normal hearing. This difference was statistically significant $(p<0.05)(76)$.

Through experiments conducted in our laboratory, various nutrient compounds have been identified that enhance mitochondrial function by their ability to protect and repair age-induced damage to cochlear mtDNA (Fig. 3). One such compound is acetyl Lcarnitine. In one study involving Fischer rats, it was noted that auditory thresholds actually improved over 
(A)

\begin{tabular}{|lllllllll|}
\hline 1 & 2 & 3 & 4 & 5 & 6 & 7 & 8 \\
\hline
\end{tabular}

(B)

\begin{tabular}{|llllllllll|}
\hline 1 & 2 & 3 & 4 & 5 & 6 & 7 & 8 \\
\hline & & & & & & & & \\
\hline
\end{tabular}

Fig. 3. (A) Data for the identification of ND1-16S rRNA from stria vascularis. This represents a $601 \mathrm{bp}$ product and verifies the integrity of the PCR and the presence of mitochondrial DNA. Lane 1: negative control; lane 2: placebo; lane 3: diet restriction; lane 4: vitamin $\mathrm{C}$; lane 5: vitamin E; lane 6: melatonin; lane 7: lazaroid; lane 8: molecular weight standards. (B) Data identifying the 4834 bp deletion (common aging deletion) from stria vascularis. This represents a 597 bp product. Lane 1: negative control; lane 2: placebo; lane 3: diet restriction; lane 4: vitamin $C$; lane 5: vitamin $\mathrm{E}$; lane 6: melatonin; lane 7: lazaroid; lane 8: molecular weight standards. The DNA concentration was normalized to $150 \mathrm{ng}$ for all samples.

the course of 6 weeks, suggesting a strong positive role for these compounds (77) (Fig. 4). In another study, our laboratory investigated the effects of lecithin on aging and age-associated hearing loss in rats by measuring hearing sensitivities using auditory brainstem responses (ABR). In addition, mitochondrial function, as a measure of aging, was assessed by determining mitochondrial membrane potentials. This was achieved using flow cytometry and by amplifying mitochondrial DNA deletions associated with aging using PCR. Harlan-Fischer rats, aged 18-20 months $(n=14)$, were divided into two groups. The experimental group was supplemented orally for 6 months with lecithin, a purified extract of soybean phospholipid (Nutritional Therapeutics, Allendale, NJ, USA). The data obtained were compared with the control group. ABR were recorded at 2-month intervals and showed significant preservation of hearing sensitivities in the treated subjects. Flow cytometry revealed mitochondrial membrane potentials to be significantly higher in the treated subjects, suggesting preserved mitochondrial function. Finally, the common aging mitochondrial DNA deletion $\left(\mathrm{mtDNA}^{4834}\right)$ were amplified from brain and cochlear tissue, including stria vascularis and auditory nerve. This specific deletion was quantitatively found to be fewer in all tissues in the treated group compared with the controls. Based on these findings, these experiments support our hypothesis and provide evidence that lecithin may preserve cochlear mitochondrial function and protect from hearing loss associated with aging.

Caloric restriction has also been shown to retard the aging process. In a study conducted by Lee et al. (78), a control and calorie-restricted group of mice were compared over a 30-month period, and the results revealed that age-related changes in gene expression profiles were remarkably attenuated by caloric restriction. During aging there is a lower expression of metabolic and biosynthetic genes, and caloric restriction was noted to decrease the normal age-induced genetic alterations by causing a metabolic shift toward increased protein turnover and decreased macromole-
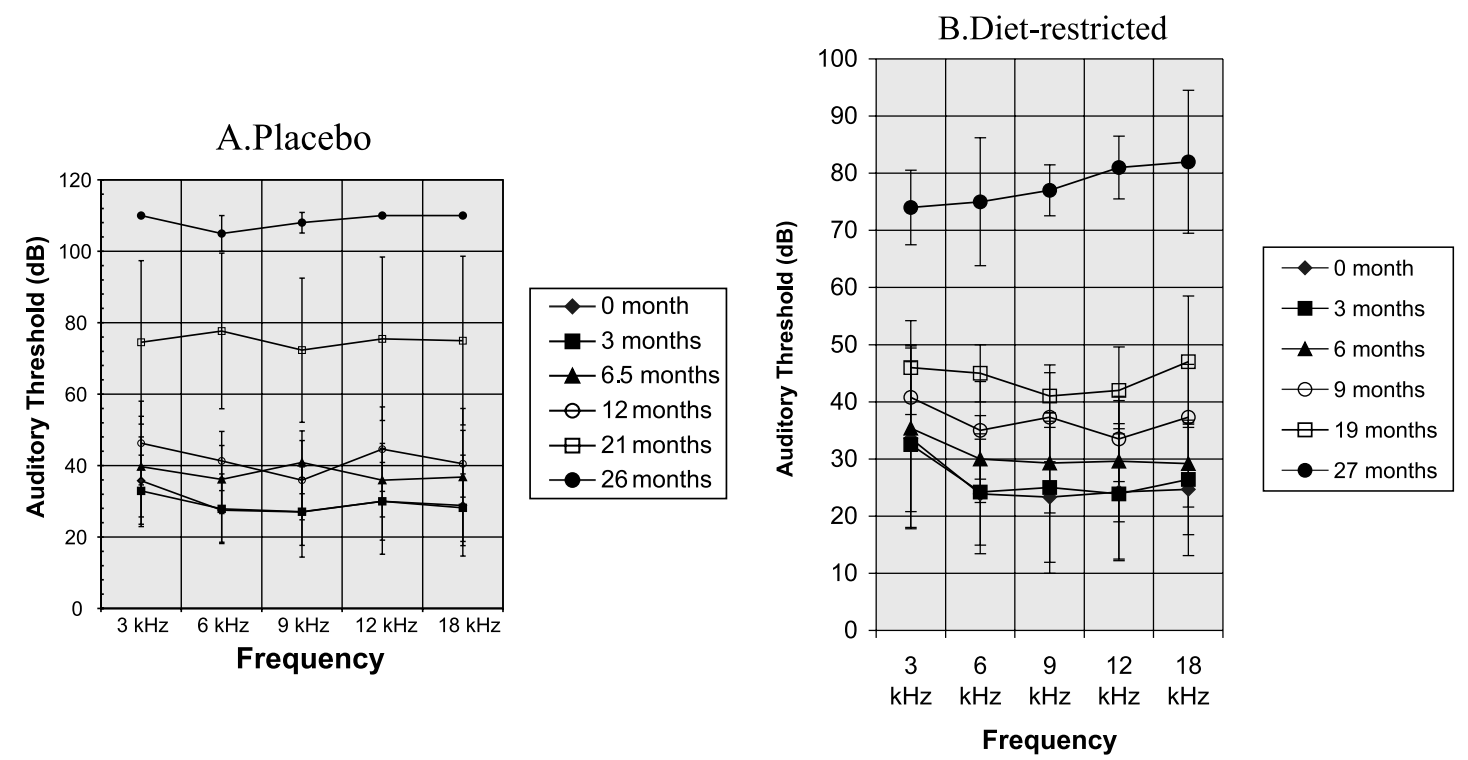

Fig. 4. Auditory threshold measurements in (A) placebo and (B) diet-restricted groups. Over the lifespan of 24-27 months, the thresholds shifted the least in diet-restricted groups. The difference between diet-restricted groups and placebo was statistically significant $(\mathrm{p}<0.01)$. 
cular damage, hence creating a more bioenergetically efficient cell. Another study by Lee et al. (79) demonstrated that caloric-restricted mice produced fewer proteins associated with the oxidative stress response and heat shock factors.

\section{DISCUSSION}

Presbyacusis, or the progressive deterioration of hearing associated with aging, is the most common cause of adult auditory deficiency in the USA. This condition creates a significant burden not only for the sufferers, but also for those who communicate with them. The medical and socioeconomic costs are staggering, and with the expansion of the world population and the numbers of elderly individuals expecting to more than double by the year 2030, this problem is escalating. However, significant progress has been made to identify the molecular mechanisms of age-related hearing loss, and this in turn has led to research on methods of mitigating the adverse effects on the auditory system. Among the various mechanisms that are postulated to result in age-related hearing loss in the current literature, the one that is arguably the most intriguing, is the membrane hypothesis of aging (MHA). Also known as the mitochondrial clock theory of aging, the premise of this theory is that with aging, hypoperfusion of the cochlear tissue occurs, which leads to ischemia and the formation of ROS. These species are highly toxic substances that adversely affect the auditory neuroepithelia. More specifically, these ROS damage mitochondrial DNA (mtDNA), resulting in both the production of specific mtDNA deletions, as well as reducing the mitochondrial membrane potential (MMP). The resultant effect is to render the mitochondria bioenergetically inefficient. These specific mtDNA deletions are also known as the common aging deletion. Studies are increasingly supportive of this relationship between presbyacusis and the common aging deletion.

The results of these studies have further led to investigations concerning the role of antioxidants, nutritional supplementation, and dietary restriction on hearing loss and the aging process in general There is compelling evidence to suggest that the beneficial effect of these compounds is to slow down the 'mitochondrial clock', by decreasing the amount of mtDNA deletions and causing less of a reduction in mitochondrial membrane potential. Currently, our laboratory is investigating the role of resveratrol, a constituent of the red wine grape, in attenuating the age-induced reductions in auditory sensitivity; specifically, its antioxidant effect on the mitochondrial apparatus. This study will hopefully provide strong empirical evidence of an integrated hypothesis of aging and presbyacusis, with the ultimate goal of enhancing our understanding of the mechanisms that surround senescence, both as a phenomenon and as an intrinsic biological property.

\section{REFERENCES}

1. Prazma J, Carrasco VN, Butler B, Waters G, Anderson T, Pillsbury HC. Cochlear microcirculation in young and old gerbils. Arch Otolaryngol Head Neck Surg 1990; 116: $932-6$.

2. Seidman MD, Khan MJ, Dolan DF, Quirk WS. Agerelated differences in cochlear microcirculation and auditory brain stem response. Arch Otolaryngol Head Neck Surg 1996; 122: 1221-6.

3. Gacek MR, Schuknecht HF. Pathology of presbyacusis. Int Audiol 1969; 8: 199-209.

4. Harkins SW. Effects of age and interstimulus interval on brainstem auditory evoked potential. Int $\mathbf{J}$ Neurosci 1981; 15: 107-18.

5. Rosenhall U, Pederson K, Dotevall M. Effects of presbyacusis and other types of hearing loss on auditory brain stem responses. Scand Audiol 1986; 15: 179-85.

6. Hoeffding V, Feldman ML. Changes with age in the morphology of the cochlear nerve in rats: light microscopy. J Comp Neurol 1988; 276: 537-46.

7. Cortopassi GA, Arnheim N. Detection of a specific mitochondrial DNA deletion in tissues of older humans. Nucleic Acids Res 1990; 18: 6927-33.

8. Corral-Debrinski M, Stepien G, Shoffner JM, et al. Hypoxemia is associated with mitochondrial DNA damage and gene induction: implications for cardiac disease. JAMA 1991; 266: 1812-6.

9. Hattori K, Tanaka M, Sugiyama S, et al. Age-dependent increase in deleted mitochondrial DNA in the human heart: possible contributory factor to presbyacusis. Am Heart J 1991; 121(6, Pt 1): 1735-42.

10. Seidman MD, Quirk WS, Nuttall AL, Schweitzer VG. The protective effects of allopurinol and superoxide dismutase-polyethylene glycol on ischemic and reperfusion-induced cochlear damage. Otolaryngol Head Neck Surg 1991; 105: 457-63.

11. Wallace DC. Diseases of the mitochondrial DNA. Annu Rev Biochem 1992; 61: 1175-212.

12. Semsei I, Szeszek F, Nagy I. In vivo studies of age dependent decrease of the rates of total and mRNA synthesis in the brain cortex of rats. Arch Gerontol Geriatr 1982; 1: 29-42.

13. Kudo T, Ikeda K, Oshima T, et al. GJB2 (connexin 26) mutations and childhood deafness in Thailand. Otol Neurotol 2001; 22: 858-61.

14. Strehler BL. Genetic instability as the primary cause of human aging. Exp Gerontol 1986; 21: 283-319.

15. Pommier JP, Lebeau J, Ducray C, et al. Chromosomal instability and alteration of telomere repeat sequences. Biochimie 1995; 77: 817-25.

16. Shay JW, Wright WE. Telomerase activity in human cancer. Curr Opin Oncol 1996; 8: 66-71.

17. Hiyama K, Hirai Y, Kyoizumi S, et al. Activation of telomerase in human lymphocytes and hematopoietic progenitor cells. J Immunol 1995; 155: 3711-5. 
18. Hockenberry DM, Otlvai ZN, Yin XM, Milliman CL, Korsmeyer SJ. Bcl-2 functions in an antioxidant pathway to prevent apoptosis. Cell 1993; 75: 241-52.

19. Kane DJ, Sarafian TA, Anton R, et al. Bcl-2 inhibition of neural cell death: decreased generation of reactive oxygen species. Science 1993; 262: 1274-7.

20. Korsmeyer SJ, Yin XM, Oltvai ZN, Veis-Novack DJ, Linette GP. Reactive oxygen species and regulation of cell death by the Bcl-2 gene family. Biochim Biophys Acta 1995; 1271: 63-6.

21. Oltvai ZN, Milliman CL, Korsmeyer SJ. Bcl-2 heterodimerizes in vivo with a conserved homolog, Bax, that accelerates programmed cell death. Cell 1993; 74: 60919.

22. Sohal RS, Allen RG. Relationship between metabolic rate, free radicals, differentiation and aging: a unified theory. Basic Life Sci 1985; 35: 75-104.

23. Southorn PA, Powis G. Free radicals in medicine, I: chemical nature and biologic reactions. Mayo Clin Proc 1988; 63: 381-9.

24. Zy-Nagy I, Semsei I. Centrophenoxine increases the rates of total and mRNA synthesis in the brain cortex of old rats: an explanation of its action in terms of the membrane hypothesis of aging. Exp Gerontol 1984; 19: $171-8$.

25. Zs-Nagy I, Cutler RG, Semsei I. Dysdifferentiation hypothesis of aging and cancer: a comparison with the membrane hypothesis of aging. Ann N Y Acad Sci 1988; 521: 215-25.

26. Moon H, Baek D, Lee B, et al. Soybean ascorbate peroxidase suppresses Bax-induced apoptosis in yeast by inhibiting oxygen radical generation. Biochem Biophys Res Commun 2002; 290: 457-62.

27. Johnson KR, Erway LC, Cook SA, Willott JF, Zheng QY. A major gene affecting age-related hearing loss in C57BL/6J mice. Hear Res 1997; 114: 83-92.

28. Staeker H, Zheng QY, Van de Water TR. Oxidative stress in aging in the C57B16/J mouse cochlea. Acta Otolaryngol 2001; 121: 666-72.

29. Davis RR, Newlander JK, Ling X, Cortopassi GA, Krieg EF, Erway LC. Genetic basis for susceptibility to noise-induced hearing loss in mice. Hear Res 2001; 155: $82-90$.

30. Crowley DE, Swain RE, Schramm VL, Swanson SN. Analysis of age-related changes in electric responses from the inner ear of rats. Ann Oto Rhinol Laryngol 1972; 81: 739-46.

31. Crowley DE, Schramm VL, Swain RE, Swanson SN. Age-related waveform changes of 8th nerve action potentials in rats. Laryngoscope 1973; 83: 264-75.

32. Simpson GV, Knight RT, Brailowsky S, Prospero-Garcia $\mathrm{O}$, Scabini D. Altered peripheral and brainstem auditory function in aged rats. Brain Res 1985; 348: 28-35.

33. Seidman MD, Shivapuja BG, Quirk WS. The protective effects of allopurinol and superoxide dismutase on noise-induced cochlear damage. Otolaryngol Head Neck Surg 1993; 109: 1052-6.

34. Seidman MD, Bai U, Khan MJ, Quirk WS. Mitochondrial DNA deletions associated with aging and presbyacusis. Arch Otolaryngol Head Neck Surg 1997; 123: 1039-45.

35. Soucek S, Michaels L, Frohlich A. Pathological changes in the organ of Corti in presbyacusis as revealed by microslicing and staining. Acta Otolaryngol Suppl 1987; 436: $93-102$.
36. Johnsson LG, Hawkins JE Jr. Sensory and neural degeneration with aging, as seen in microdissections of the human inner ear. Ann Otol Rhinol Laryngol 1972; 81: 179-93.

37. Nadol JB Jr. Application of electron microscopy to human otopathology Ultrastructural findings in neural presbyacusis, Meniere's disease and Usher's syndrome. Acta Otolaryngol 1988; 105: 411-9.

38. Willott JF, Milbrandt JC, Bross LS, Caspary DM. Glycine immunoreactivity and receptor binding in the cochlear nucleus of $\mathrm{C} 57 \mathrm{BL} / 6 \mathrm{~J}$ and $\mathrm{CBA} / \mathrm{CaJ}$ mice: effects of cochlear impairment and aging. J Comp Neurol 1997; 385: 405-14.

39. Keithley EM, Feldman ML. Hair cell counts in an agegraded series of rat cochleas. Hear Res 1982; 8: 249-62.

40. Kurylo DD, Corkin S, Allard T, Zatorre RJ, Growdon $\mathrm{JH}$. Auditory function in Alzheimer's disease. Neurology 1993; 43: 1893-9.

41. Sinha UK, Hollen KM, Rodrigues R, Miller CA. Auditory system degeneration in Alzheimer's disease. Neurology 1993; 43: 779-85.

42. Gates GA, Karzon RK, Garcia P, et al. Auditory dysfunction in aging and senile dementia of the Alzheimer's type. Arch Neurol 1995; 52: 626-34.

43. Halliwell B, Gutteridge JM, Cross CE. Free radicals, antioxidants, and human disease: where are we now? J Lab Clin Med 1992; 119: 589-620.

44. Halliwell B. Free radicals and antioxidants: a personal view. Nutr Rev 1994; 52(8 Pt 1): 253-65.

45. Byers T, Bowman B. Vitamin E supplements and coronary heart disease. Nutr Rev 1993; 51: 33-6.

46. Comstock GW, Helziouser KJ, Bush TL. Prediagnostic serum levels of carotenoids and vitamin $\mathrm{E}$ as related to subsequent cancer in Washington County, Maryland. Am J Clin Nutr 1991; 53(1 Suppl): 260S-4.

47. Ziegler RG. Vegetables, fruits and carotenoids and the risk of cancer. Am J Clin Nutr 1991; 53(1 Suppl): 251S-9.

48. Smith MA, Perry G. Free radical damage, iron and Alzheimer's disease. J Neurol Sci 1995; 134(Suppl): $92-4$.

49. Lyras L, Cairns NJ, Jenner A, Jenner P, Halliwell B. An assessment of oxidative damage to proteins, lipids and DNA in brain from patients with Alzheimer's disease. J Neurochem 1997; 68: 2091-9.

50. Sheehan JP, Swerdlow RH, Miller SW, et al. Calcium homeostasis and reactive oxygen species production in cells transformed by mitochondria from individuals with sporadic Alzheimer's disease. J Neurosci 1997; 17: 4612-22.

51. Choi BH. Oxygen, antioxidants and brain dysfunction. Yonsei Med J 1993; 34: 1-10.

52. Jenner P, Olanow CW. Oxidative stress and the pathogenesis of Parkinson's disease. Neurology 1996; 47 (6 Suppl 3): S161-70.

53. Klein JA, Longo-Guess CM, Rossmann MP, et al. The harlequin mouse mutation downregulates apoptosisinducing factor. Nature 2002; 419: 367-74.

54. Wallace DC, Zheng X, Lott MT, et al. Familial mitochondrial encephalomyopathy (MERRF): genetic, pathophysiological, and biochemical characterization of a mitochondrial DNA disease. Cell 1988; 55: 601-10.

55. Wallace DC, Lott MT, Lezza AM, et al. Mitochondrial DNA mutations associated with neuromuscular diseases: analysis and diagnosis using polymerase chain reaction. Pediatric Res 1990; 28: 525-8. 
56. Yen TC, Chen YS, King KL, et al. Liver mitochondrial respiratory functions decline with age. Biochem Biophys Res Commun 1989; 165: 944-1003.

57. Lindane AW, Marzuki S, Ozawa T, et al. Mitochondrial DNA mutations as an important contributor to aging and degenerative diseases. Lancet 1985; i: 642-5.

58. Shoffner JM, Lott MT, Voljavec AS, et al. Spontaneous Kearn-Sayre/Chronic External Ophthalmoplegia Plus Syndrome associated with a mitochondrial DNA deletion: a slip replication model and metabolic therapy. Proc Natl Acad Sci U S A 1989; 86(20): 7952-6.

59. DiMauro S, Bonilla E, Lombes A, et al. Mitochondrial encephalomyopathies. Neurol Clin 1990; 8: 483-506.

60. Grossman LI. Mitochondrial DNA in sickness and health. Am J Hum Genet 1990; 46: 415-7.

61. Pavlakis SG, Phillips PC, DiMauro S, et al. Mitochondrial myopathy, encephalopathy, lactic acidosis, and stroke-like episodes: a distinctive clinical syndrome. Ann Neurol 1984; 16: 481-8.

62. Seibel P, Degoul F, Romero N, et al. Identification of point mutations by mispairing PCR as exemplified by MERRF disease. Biochem Biophys Res Commun 1990; 173: $561-5$.

63. Gold M, Rapin I. Non-Mendelian mitochondrial inheritance as a cause of progressive geneticsensori-neural hearing loss. Int J Pediatr Otorhinolaryngol 1994; 30: 91-104.

64. Ames BN. Dietary carcinogens and anticarcinogens. Oxygen radicals and degenerative diseases. Science 1983; 221: 1256-64.

65. Wallace DC. Mitochondrial DNA in aging and disease. Sci Am 1997; 277: 40-7.

66. Nohl H, Hegner D. Do mitochondria produce oxygen radicals in vivo? Eur J Biochem 1978; 82: 563-7.

67. Piko L, Hougham AJ, Bulpitt AJ. Studies of sequence heterogeneity of mitochondrial DNA from rat and mouse tissues: evidence for an increased frequency of deletions/additions with aging. Mech Ageing Dev 1988; 43: 279-93.

68. Muller-Hocker J. Cytochromec-oxidase deficient cardiomyocytes in the human heart - an age-related phenomenon. A histochemical, ultracytochemical study. Am J Pathol 1989; 134: 1167-73.

69. Bandy B, Davison AJ. Mitochondrial mutations may increase oxidative stress: implications for carcinogenesis and aging? Free Radic Biol Med 1990; 8: 523-39.

70. Gold M, Rapin I, Shankse S. Mitochondrial inheritance of acquired deafness. Ann N Y Acad Sci 1991; 630: $301-2$.
71. Miyabayashi S, Hanamizu H, Endo H, et al. A new type of mitochondrial DNA deletion in patients with encephalomyopathy. J Inherit Metab Disease 1991; 14: 805-12.

72. Ballinger SW, Shoffner JM, Hedaya EV, et al. Maternally transmitted diabetes and deafness associated with a 10.4 Kb mitochondrial DNA deletion. Nat Genet 1992; 1: $11-5$.

73. Van den Ouweland JM, Lemkes HH, Ruitenbeek W, Sankuijl LA. Mutation in mitochondrial tRNA(Leu) (UUR) gene in large pedigree with maternally transmitted type II diabetes mellitus and deafness. Nat Genet 1992; 1: 368-71.

74. Sawada S, Takeda T, Kakigi A, et al. Audiological findings of sensorineural deafness associated with a mutation in the mitochondrial DNA. Am J Otol 1997; 18: $332-5$.

75. Ueda N, Oshima T, Ikeda K, et al. Mitochondrial DNA deletion is a predisposing cause for sensorineural hearing loss. Laryngoscope 1998; 108(4 Pt 1): 580-4.

76. Bai U, Seidman MD, Hinojosa R, Quirk WS. Mitochondrial DNA deletions associated with aging and possibly presbyacusis: a human archival temporal bone study. Am J Otol 1997; 18: 449-53.

77. Seidman MD, Khan MJ, Bai U, Shirwany N, Quirk WS. Biologic activity of mitochondrial metabolites on aging and age-related hearing loss. Am J Otol 2000; 21: 161-7.

78. Lee CK, Klopp RG, Weindruch R, Prolla TA. Gene expression profile of aging and its retardation by caloric restriction. Science 1999; 285: 1390-3.

79. Lee CK, Weindruch R, Prolla TA. Gene-expression profile of the ageing brain in mice. Nat Genet 2000; 25: 294-7.

Address for correspondence:

Michael D. Seidman, MD, FACS

Department of Otolaryngology-Head \& Neck Surgery

Director-Division tologic/Neurotologic Surgery

Henry Ford Health System

Director-Complementary/Integrative Medicine

6777 W. Maple Road

W. Bloomfield

MI 48323

USA

Tel: +12486617211

Fax: +1 2486616456

E-mail: mseidma1@hfhs.org 